\title{
APRENDER JUGANDO CON “TEJIDOS PRECOLOMBINOS" MEDIANTE ROMPECABEZAS VIRTUALES
}

\section{LEARN BY PLAYING WITH “PRE-COLUMBIAN TEXTILES” THROUGH VIRTUAL PUZZLES}

\author{
Diego Aracena Pizarro ${ }^{1} \quad$ Yerko Paredes Orellana $^{2} \quad$ Julia Córdova-González $^{3}$
}

Recibido 3 de enero de 2008, aceptado 8 de septiembre de 2008

Received: January 3, 2008 Accepted: September 8, 2008

\begin{abstract}
RESUMEN
Este trabajo presenta un ambiente multimedia de rompecabezas sobre tejidos precolombinos de gran complejidad ornamental, expuestos en el Museo Arqueológico San Miguel de Azapa, Arica-Chile. El rompecabezas permite interaccionar de manera más entretenida y didáctica, con el objetivo de que la facilidad del uso del software permita aprender jugando, observando los intrincados símbolos y signos precolombinos que de otra manera pasan desapercibidos por no formar parte del ideario de los estudiantes actuales. El software se evaluó con alumnos de enseñanza básica y media de establecimientos educacionales de la ciudad, con el objetivo de complementar sus estudios a las asignaturas de historia que contienen temática prehispánica.

Esta representación educacional fue implementada con herramienta Flash multimedia, con el propósito de estimular la parte creativa de los estudiantes y de abrir un mundo de juegos complementarios referentes al mismo tema, con la filosofía de aprender jugando.
\end{abstract}

Palabras clave: Usabilidad de software, multimedia, tejidos andinos, arqueología precolombina.

\begin{abstract}
This paper presents a multimedia environment puzzle about Pre-Columbian textiles exhibiting ornamental complexities, found in the Archeological Museum San Miguel de Azapa, Arica-Chile. The software allows an enjoyable and didactic interactive way of learning by playing, giving the users the opportunity of identifying intricate pre-Columbian symbols and signals, that otherwise would be unnoticed. The software was tested with schoolboys of ages 12 to 16 years old, from schools in Arica, with the purpose of complementing their studies in History courses containing Pre-hispanic topics. This educational software was implemented with Multimedia Flash Tool, so as to stimulate the creativity of the students, opening a world of complementary games with the philosophy of "learning by playing".
\end{abstract}

Keywords: Software, usability, multimedia, andean textiles, pre-Columbian archaeology.

\section{INTRODUCCIÓN}

Los arqueólogos han denominado cultura Arica al conjunto de sociedades que habitaron los valles y costa de Arica entre los años 1000 a 1400 d.C., es decir, entre el fin del Estado Tiwanaku (Bolivia) y la expansión del estado Inca desde el Cuzco. La cultura Arica comprende el desarrollo político, social, económico y simbólico más relevante de la historia local y permite explicar gran parte de las singularidades de la región Arica y Parinacota.

La artesanía regional se caracteriza por los diseños y figuras en tejidos de formas y colores que expresan el lenguaje del hombre andino. Patrones que fueron heredados por los

\footnotetext{
1 Escuela Universitaria de Ingeniería Industrial, Informática y de Sistemas. Área de Ingeniería en Computación e Informática. Universidad de Tarapacá. Arica, Chile. E-mail: daracena@uta.cl

2 Estudiante Magíster de Ingeniería de Software. Escuela Universitaria de Ingeniería Industrial, Informática y de Sistemas. Universidad de Tarapacá. Arica, Chile. E-mail: yparedeso@gmail.com

3 Departamento de Antropología. Universidad de Tarapacá. Arica, Chile. E-mail: jcordova@uta.cl
} 
actuales artesanos, quienes los reproducen fielmente en sus trabajos. Estos trabajos son tejidos realizados con lana de camélido o algodón, hilada y torcida, entrecruzando las fibras. Con la técnica del telar (urdimbre y trama) se elaboraron bolsas, camisas y paños rituales. Otra técnica utilizada es el trenzado plano, para la confección de fajas con decoración estrellada.

Los tejidos andinos y la antigüedad de estos, cuya interpretación está evaluada por la ciencia, contienen una difusión de contenidos, que no van a la par con la importancia del aporte que representan para la ciencia y la cultura nacional y universal, por lo que se hace necesario realizar un ambiente educativo que permita dar a conocer de una manera atractiva e interactiva un mundo que siempre ha estado presente [11]. Este ambiente educativo permite lograr un aprendizaje a través de juegos digitales, por intermedio de la "Computación Gráfica" y técnicas multimediales que permitan desarrollar un ambiente virtual.

Aprender jugando con aplicaciones interactivas de tejidos precolombinos nos permite desarrollar habilidades sobre la interpretación de símbolos y signos, esto permite formarnos una idea particular sobre cada objeto visto, posibilitando un aprendizaje de manera más atractiva y divertida, que nos deja las puertas abiertas de seguir interiorizándonos acerca de la cultura andina expuesta en el Museo Arqueológico San Miguel de Azapa.

La idea principal de estos juegos es desarrollar un ambiente virtual que permita integrarlos en el aprendizaje de tejidos precolombinos. Este ambiente virtual es el de rompecabezas en 2D que darán la representación de vestimentas típicas de los pueblos indígenas. Estos juegos en ambientes virtuales permiten a los usuarios interaccionar con los tejidos de manera más entretenida y didáctica, como forma de dar a conocer a la comunidad asistente que con el ambiente se permite incentivar la creatividad aprendiendo y a la vez jugando, tal como en el trabajo de Wiberg y Jegers [4] que especifica la satisfacción que resulta el aprendizaje mediante juegos.

El ambiente virtual de rompecabezas fue evaluado por alumnos de enseñanza básica y media de establecimientos educacionales de la ciudad, con el objetivo de complementar sus estudios correspondientes a asignaturas de historia que contienen cierta temática prehispánica. Este software multimedial será exhibido en las dependencias del Museo San Miguel de Azapa, Arica-Chile.

En este trabajo se presenta la situación actual de este tipo de juegos, el modelamiento del presente juego, la interfaz del juego en base a su modelamiento previo y los resultados obtenidos mediante la evaluación del software en una muestra de alumnos de la misma ciudad.

\section{TRABAJOS EXISTENTES}

En la actualidad se puede señalar que existen bastantes trabajos realizados bajo ambientes virtuales en museos, que representan diferentes periodos culturales. La gama y el alcance de estos juegos culturales educativos varían considerablemente. Como proyectos en Escocia, sobre monumentos interactivos y juegos tridimensionales como el del modelado del valle de Kilmartin trabajado por Winterbottom y Long [8]. Otro complejo proyecto llamado Virtual Qumran (VQ) [12] trata de un viaje en línea de las cuevas y del sitio arqueológico en Qumran que substituya el viaje actual de las cuevas. El visitante podrá aprender sobre las actividades tratadas ahí. En otra sección, el visitante podrá comparar la cerámica hecha en Qumran, además aprender sobre los estilos de vida y la creencia de diversas comunidades y sobre técnicas científicas modernas del análisis de la cerámica, entre otras cosas. También juegos conocidos como Prismaker permiten diferenciar de forma educativa la comparación de aprendizaje obtenida por un juego virtual versus un juego real [1-3], para ambientes virtuales que permitan observar las capacidades educativas que presentan los juegos virtuales frente a los juegos reales (físicos).

Algunos de estos juegos virtuales ayudan a entender juegos verdaderos de una cultura dada, como la muestra a través de realidad virtual de la cultura Maya [9].

En el ámbito local se podría decir que existe poca evidencia sobre ambientes virtuales en museos, pero existen algunas aproximaciones que dieron frutos en años anteriores, como el software educativo Yatiqasiña [10], que pretendía captar el interés del usuario por la cultura Chinchorro mediante diferentes ambientes; motivacional [7], que contenía información y permitía simular una visita al museo tanto en $2 \mathrm{D}$ como en $3 \mathrm{D}$; autoaprendizaje, que presentaba una serie de procedimientos y estrategias de aprendizaje; autoevaluación, resolución de problemas sobre los aprendizajes de los ambientes anteriores, con esto el usuario aprendía mediante novelas, películas o juegos.

Este trabajo y los analizados persiguen un fin similar, que es el aprender jugando a través de un entorno virtual entretenido y de fácil uso. Lo novedoso es que este ambiente virtual se presenta bajo un contexto muy simple, ya que tanto usuarios adultos como menores 
pueden manejar estas aplicaciones de manera fácil, lo que contribuye a un rápido e inmediato aprendizaje. Es más, con juegos muy populares como un rompecabezas, se puede llegar de forma más inmediata al usuario, de manera que el aprendizaje sea de forma eficaz e intuitiva.

\section{MODELAMIENTO DEL JUEGO}

El proyecto de ambiente virtual define un modelo de interfaz para un ambiente de juegos de rompecabezas presentados en un menú principal. Para la realización de este modelo se siguió un ciclo de vida correspondiente al proceso de la construcción de este ambiente virtual de juegos, siguiendo un modelo de proceso de la ingeniería de usabilidad [5-6].

\section{Ciclo de vida de desarrollo}

Este ciclo de vida correspondió al uso de prototipos, ya que es más flexible a la hora de hacer modificaciones. De esta manera se presenta una versión anticipada del software al conjunto de usuarios que corresponderá a la evaluación.

\section{REQUERIMIENTOS}

\section{Requerimientos de la aplicación}

- El usuario tendrá acceso a un menú principal que le proporcionará el comienzo del juego.

- El ambiente tendrá cinco juegos de diferentes niveles.

- El juego tendrá música de fondo.

- El juego tendrá un video de ayuda.

\section{Requerimientos de la interacción en el juego}

- Al posicionarse el puntero del mouse en algún nombre de tejido se desplegará información tanto textual como auditiva acerca de la descripción del tejido.

- Cada rompecabezas tendrá tres botones:

o Ver imagen: Al posicionarse el puntero del mouse se mostrará la imagen de forma muy breve como modo de ayuda.

o Jugar de nuevo: Permitirá jugar nuevamente.

o Volver a menú: Permitirá volver a menú principal.
- La ayuda en video indicará tanto textual como auditiva la forma de armar un rompecabezas. Contando con botones de funcionalidad al igual que un reproductor de video.

\section{Requerimientos no funcionales}

- Podrá acceder al juego cualquier persona que instale el juego

- El juego podrá ser operado bajo ambiente Windows o de forma alternativa podrá ser visualizado en cualquier navegador Web que proporcione Flash player, soportado en todo sistema operativo.

\section{Diseño}

Para diseñar la aplicación se utilizó el lenguaje de modelado unificado UML [6], pues este nos proporcionó la manera de construir el diseño del sistema en base a sus requerimientos.

\section{Identificación de sucesos}

La figura 1 muestra el escenario con los sucesos que ocurrirán en el juego.

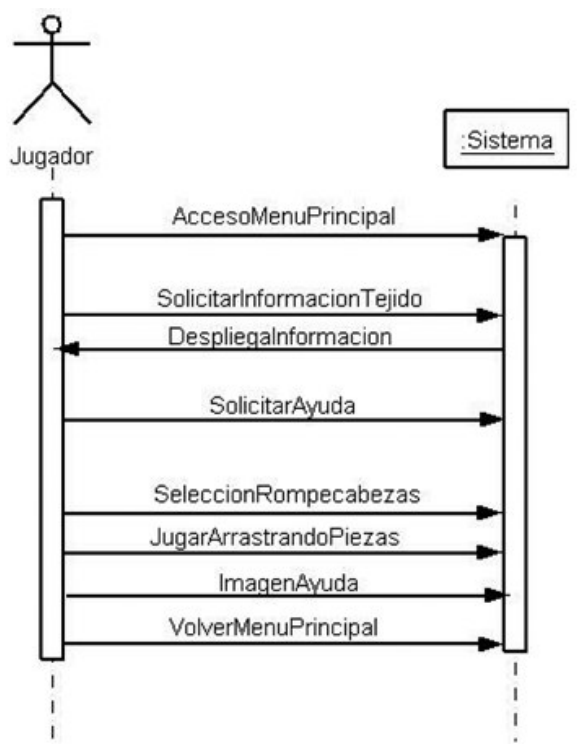

Figura 1. Escenario de sucesos.

\section{Diseño conceptual}

A través del método orientado a objetos se construirá un esquema conceptual del sistema. La figura 2 muestra el modelo conceptual generalizado del juego. 


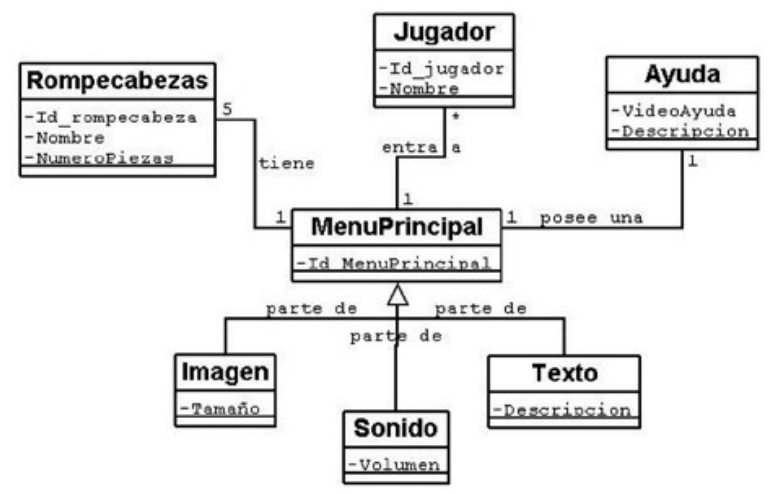

Figura 2. Modelo conceptual.

\section{Prototipo y evaluación}

Una vez realizado el diseño se construye un prototipo inicial para una posterior evaluación a través de los propios desarrolladores de este proyecto. Luego, refinados los detalles finales, se procede a la evaluación, muestra extraída de un conjunto de colegios de Arica. Los resultados de esta evaluación nos llevaron a redefinir los requerimientos para un nuevo prototipo y posterior evaluación. Datos de la evaluación serán expuestos en la sección resultados de este trabajo de investigación.

\section{INTERFAZ GRÁFICA}

Con respecto a la interfaz de estos juegos de rompecabezas, cada uno implementa una usabilidad sencilla, en la cual solo se debe usar el mouse para su funcionalidad. Con respecto a la interactividad que tienen los juegos, se puede decir que estos siguen una lógica muy clara, que es la de capturar la entereza del usuario a través de pasos muy sencillos, como un simple posicionamiento en un botón que despliega información o un click en otro botón que ejecuta una acción determinada. La sencillez de estos juegos implica una rápida comprensión de la herramienta, lo que provoca un conocimiento más profundo de lo que realmente se quiere mostrar en cada uno de estos juegos.

Esta implementación está dada de esta manera, con el fin de provocar una eficiente y rápida enseñanza a niños, jóvenes y adultos sobre juegos educacionales virtuales.

\section{Implementación del ambiente virtual del rompecabezas}

Utilizando fotos tomadas en el Museo San Miguel de Azapa, de tres tejidos precolombinos de interés, Tari (figura 3), Chuspa y Bolsa-Faja, se realizó un rompecabeza por cada foto.

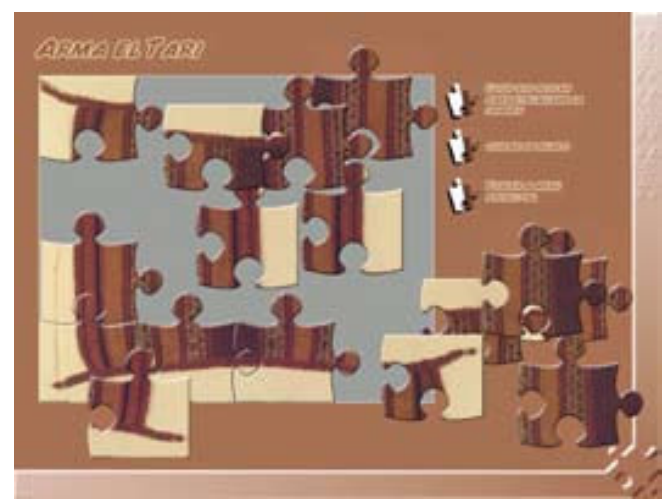

Figura 3. Rompecabezas tipo Tari.

En primer lugar, se recortan imágenes aleatoriamente en forma de piezas de rompecabezas, para luego implementar en Flash todas las funcionalidades. Como todo rompecabezas, la idea es arrastrar cada pieza hacia una sección que permita juntar todas estas piezas, con el fin de formar la imagen completa, visualizándola previamente.

Cuenta con la posibilidad de armar cinco rompecabezas descritos en un menú (Figura 4); dos de seis piezas; dos de dieciséis piezas y uno de treinta y seis piezas.

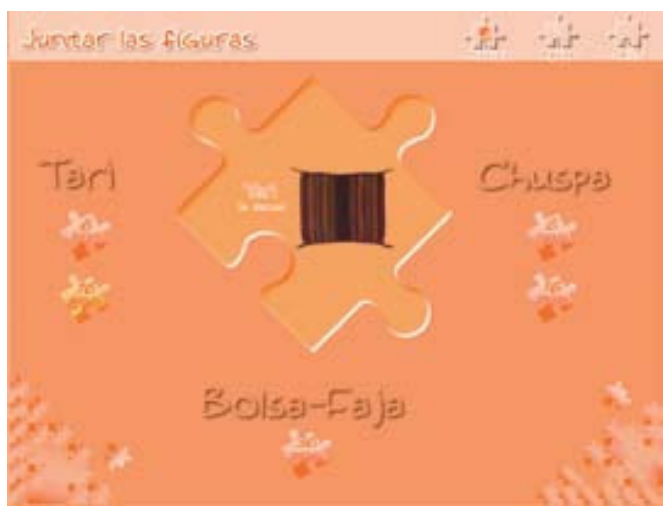

Figura 4. Menú principal.

Como parte importante del diseño de la aplicación, éste presenta una serie de opciones (Figura 5), las cuales indicarían la música, en el caso que desee escuchar música andina de fondo, la ayuda, en video y animación, y por último la opción salir de la aplicación.

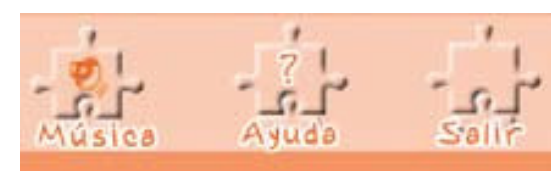

Figura 5. Opciones del menú principal. 
La ayuda (figura 6) presenta un video animado que muestra paso a paso la construcción de un rompecabezas, indicando las instrucciones de forma auditiva y textual.

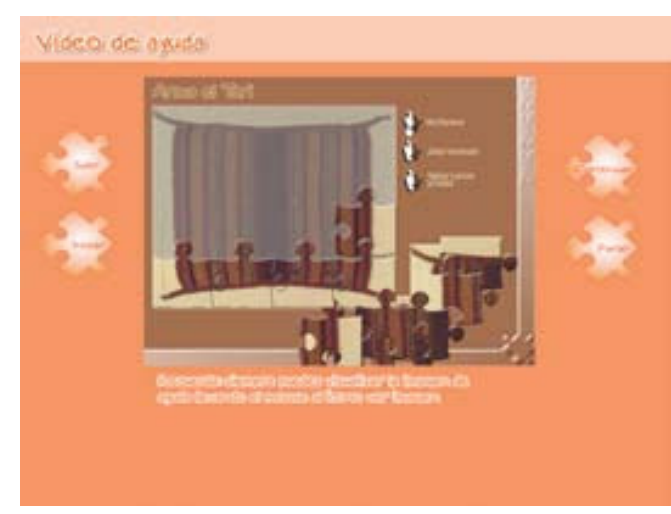

Figura 6. Video ayuda.

También cada rompecabezas contará con tres opciones, Ver imagen, Jugar de nuevo y Volver a menú principal (figura 7).

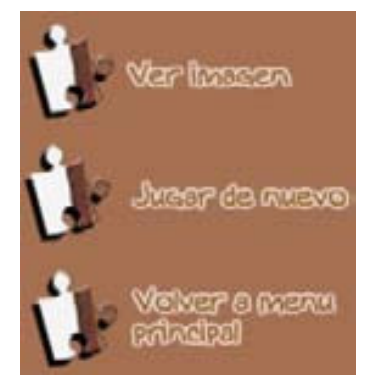

Figura 7. Opciones rompecabezas.

Por último se incorporó voz al menú principal del software (figura 4), con el propósito de que el usuario tenga la posibilidad de leer y escuchar una breve descripción del tejido. Esto es un gran apoyo a niños que todavía no saben leer y a personas que cuentan con deficiencias en la lectura, completándolo como un software multimedia educativo.

\section{Funcionamiento del rompecabezas en base al aprendizaje}

Al pasar el puntero del mouse sobre el nombre de algún tejido en el menú se escucha y muestra un breve concepto de lo que trata cada tejido, Tari, Chuspa, Bolsa-Faja (figura 8) y se asocia a fotos descriptivas sobre el texto citado. Con esto se pueden observar los tipos de vestimenta que usaban y las costumbres que tenían.

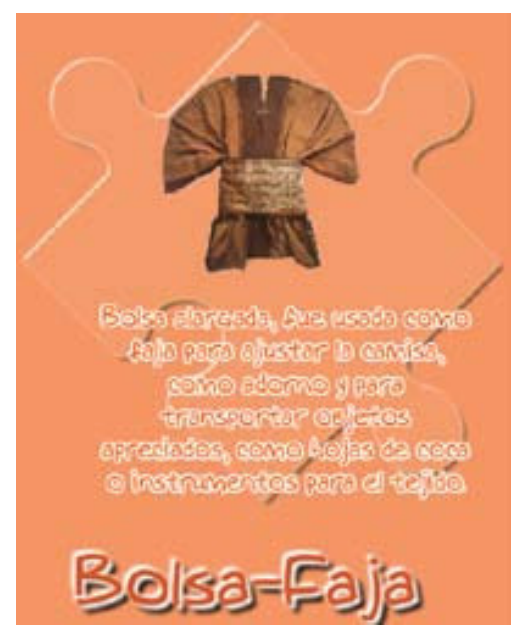

Figura 8. Descripción Bolsa-Faja.

Todo rompecabezas cuenta con un funcionamiento sencillo, el cual consiste en armar una imagen de tejido en base al número de piezas que éste tenga.

El hecho de jugar con esta sencilla aplicación mundialmente conocida nos da la oportunidad de observar la imagen final mostrada por la aplicación, una vez terminado cada rompecabezas, cuestión que realiza cualquier juego de rompecabezas, pero la importancia de esta radica en que cada imagen muestra una historia única. Además, hay que considerar que este ambiente virtual entretenido nos proporciona la oportunidad de observar imágenes inéditas de tejidos precolombinos, los cuales podemos ubicar exclusivamente en el Museo de San Miguel de Azapa, Arica-Chile.

\section{RESULTADOS}

La evaluación de este software es de carácter cuantitativo y cualitativo, en una muestra intencionada de estudiantes de enseñanza básica y media de un establecimiento público y uno privado de la ciudad de Arica-Chile.

La muestra de alumnos evaluadores fue de un total de 83 alumnos. Los primeros 50 alumnos evaluadores seleccionados fueron 20 del curso 4to básico A, 15 del curso 5to básico B y 15 del curso 1ero Medio A del Colegio Integrado Eduardo Frei M. Los restantes 33 alumnos evaluadores seleccionados fueron 15 de 4to básico y 18 de 5to básico provenientes del Colegio América.

Los alumnos de 4to básico tienen un promedio de edad de 9 años, los alumnos de 5 to básico tienen un promedio de edad de 10 años y los alumnos de 1ero medio tienen un promedio de 14 años. Ellos debieron usar el juego y 
responder una breve encuesta donde se realizaron preguntas correspondientes a la usabilidad del juego, la opinión sobre el interés despertado y al aprendizaje obtenido.

\section{Resultados cuantitativos}

Las preguntas correspondientes a la usabilidad, ¿fáciles las instrucciones para iniciar el juego? (figura 9). Una suma considerable de alumnos consideró, como lo teníamos estimado, que las instrucciones del juego eran sumamente fáciles de entender.

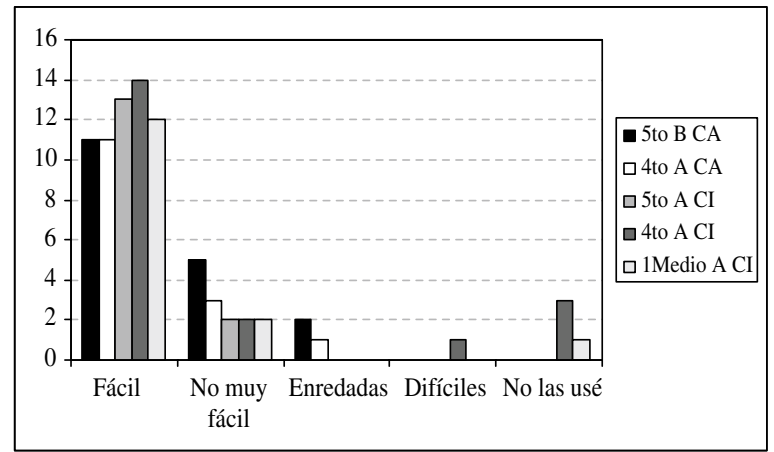

Figura 9. Facilidad inicio del juego.

¿Fácil completar los juegos? (figura 10). En este gráfico se observa una discusión con respecto a la facilidad de completar un juego; lo más relevante se presenta en que la mayoría de los alumnos de ambos colegios encuentran fácil o normal el desarrollo de un juego, mientras que un pequeño promedio (9 alumnos) del Colegio América encuentra un "poco difícil" el completar un juego.

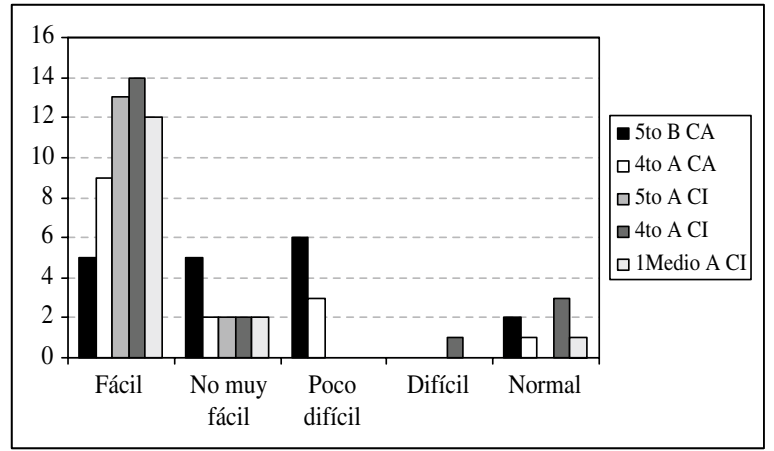

Figura 10. Facilidad en completar el juego.

¿Te gustó jugar con el software? (figura 11). Solo un alumno no opinó al respecto, mientras que tres consideraron "más o menos" el gusto por estos juegos, por otro lado, los 79 restantes consideraron que el software les gustó.

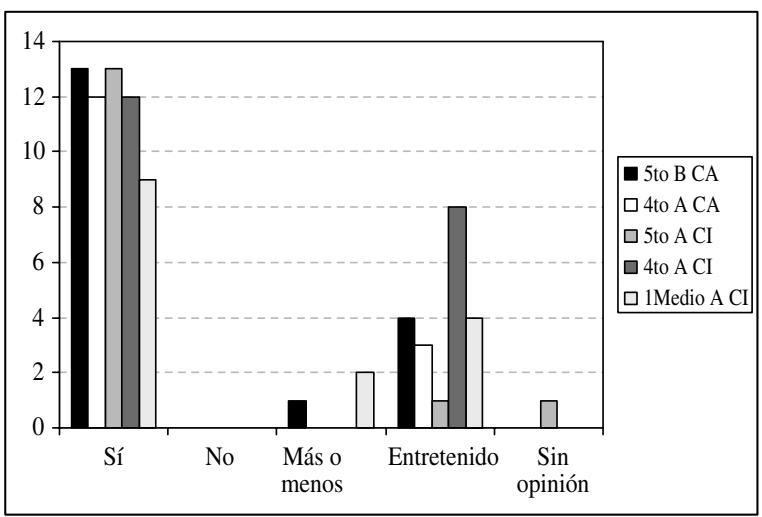

Figura 11. Nivel de satisfacción.

¿Te sirvió el botón ayuda? (figura 12). Por último, en este gráfico se puede observar una gran discusión al respecto; por un lado, los alumnos de 1ero Medio prácticamente no usaron la ayuda, mientras que una cifra considerable de alumnos de 5to básico sí les sirvió la ayuda.

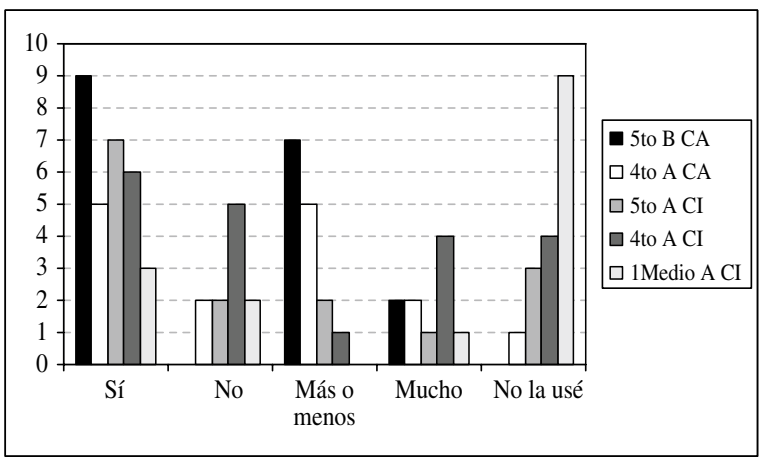

Figura 12. Uso botón de ayuda.

Al final de la encuesta se consideró un ítem que definía cuánto habían aprendido acerca de los tipos de vestimentas andinas. Para esto se establecieron las siguientes preguntas: la primera, ¿A qué corresponde este tejido?, junto a la ilustración de un tejido, con las opciones correspondientes (Tari, Chuspa o Bolsa-Faja); luego una serie de preguntas abiertas:

- ¿Qué es un Tari?

- ¿Qué es una Chuspa?

- ¿Qué es una Bolsa-Faja?

La efectividad del aprendizaje a través del juego estableció que la mayoría de los alumnos lograron asociar el tejido mostrado con el nombre respectivo; en cifras se reflejó que el $98 \%$ de los estudiantes lograron asociar el tejido con su tipo. 
En general, los alumnos evaluadores lograron relacionar las imágenes de tejidos con los cuales estos eran utilizados. Se pudo apreciar que las respuestas de los alumnos de descendencia andina les era más fácil jugar e interpretar los tejidos andinos y sus contextos en el cual se utilizaban.

\section{CONCLUSIONES}

Este ambiente virtual provocó una mayor interacción, que permite aprender de forma más entretenida acerca de los diseños, utilización y costumbres con los tejidos precolombinos, a la vez permite la posibilidad de acceder de forma no presencial a los referentes precolombinos situados en el Museo San Miguel de Azapa. El ambiente virtual de aprendizaje facilitó un estímulo para observar con mayor atención diseños y significados en los tejidos, en general, y aplicar conocimientos frente a los originales en la próxima visita al Museo.

Del punto de vista de la usabilidad, como se demostró en las encuestas aplicadas, en el software se privilegia la simpleza y el realizar un ambiente que fuera directo, de tal manera que a poco andar se pudiera rápidamente familiarizar.

En general, se observó que un software de fácil uso permite complementar el estudio de asignaturas de historia prehispánica, aprendiendo y a la vez jugando. Dicho propósito se implanta en las dependencias del Museo San Miguel de Azapa, Arica-Chile, pensando próximamente en una futura expansión, más allá de la región, con la idea de darlo a conocer al mundo.

\section{TRABAJO FUTURO}

Se está construyendo una muestra virtual en 3D de un telar andino, con el mismo propósito anterior, el de "aprender jugando", además de otros juegos que permitirán personalizar cada tejido en base a una muestra original.

\section{AGRADECIMIENTOS}

Esta investigación es parte del conjunto de software multimedia educativo en el proyecto mayor (3742, 20062007) "Evaluación de la interpretación de una muestra de tejidos precolombinos en ambiente digital”, Universidad de Tarapacá, Arica-Chile.

A Ricardo Castillo, locutor de "Radio Universidad Tarapacá”, por su colaboración en audio y sonido de la aplicación.

\section{REFERENCIAS}

[1] V. López Jaquero, F. Montero, M. Lozano, A. Fernández, P. González, M. Parra, R. López y J. Montañés. "Virtual-Prismaker: Ayudando en el proceso de aprendizaje. Juego físico vs virtual: Un solo juego dos modos de interacción". Simposio Internacional de Informática Educativa 2000, SIIE 2000. Puertollano, España. 15-17 de noviembre, 2000.

[2] P. González, F. Montero, V. López Jaquero, A. Fernández, J. Montañés and T. Sánchez. "A Virtual Learning Environment for Short Age Children". IEEE International Conference on Advanced Learning Technologies, ICALT 2001. Proceedings of the IEEE International Conference on Advanced Learning Technologies, pp. 283-285. Madison, USA. August 6-8, 2001.

[3] F. Montero, V. López Jaquero, M. Lozano, A. Fernández y P. González. "Virtual-Prismaker: Juegos de Ordenador, Educación e Interfaces". I Jornada de Interacción Persona-Ordenador, Interacción 2000. Actas I Jornada de Interacción Persona-Ordenador, pp. 263-269. Granada, España. 19-20 de junio, 2000.

[4] Ch. Wiberg and K. Jegers. "Satisfaction and Learnability in Edutainment: An usability study of the knowledge game 'Laser Challenge' at the Nobel e-museum". Accepted to HCI International. 2003.

[5] J. Lorés y T. Granollers. "Tendencias Actuales en la interacción Persona Ordenador: Accesibilidad, Adaptabilidad y Nuevos Paradigmas. Capítulo La Ingeniería de la Usabilidad aplicada al diseño y desarrollo de sitios Web”, pp. 119-144. Ediciones de la Universidad Castilla-La Mancha (Albacete, España). XIII Escuela de Verano de Informática. Julio 2003.

[6] R. Pressman. "Ingeniería del Software. Un Enfoque Práctico”. Edición sexta. Editorial McGraw-Hill, p. 992.2005.

[7] I. Ramirez, J. Córdova y R. Rodríguez. "Diseño e Implementación del módulo motivacional del proyecto Yatiqasiña". Revista de la Facultad de Ingeniería - Universidad de Tarapacá. Arica, Chile. Vol. 5. 1998. URLs: www.scielo.cl 
[8] S.J. Winterbottom and D. Long. "From abstract digital models to rich virtual environments: landscape contexts in Kilmartin Glen, Scotland". Vol. 33 Issue 10, pp. 1356-1367. October 2006.

[9] R. Ruiz, S. Weghorst, J. Savage, P. Oppenheimer, T. Furness and Y. Dozal. "Virtual reality for archaeological Maya cities". Presented at UNESCO World Heritage Conference. Mexico. December 2002.

[10] J. Córdova, Y. Ossandón, D. Aracena, I. Ramírez, J. Bernal and C. Herrera. "Interactive learning and evaluation in a Archaeological Museum Yatiqasiña a second year progress". ICOM. CECA Annual Conference. Brasil. 1999.
[11] J. Córdova-González, Y. Ossandón Núñez, D. Aracena Pizarro, L. Ulloa Torres y N. Álvarez Rosales. "Evaluación de la Interpretación de una Muestra de Tejidos Precolombinos en Ambiente Digital". Investigando y educando: estudios para el análisis y la aplicación. Actas de las 7tas Jornadas Interuniversitarias de Investigación, p. 359. Octubre 2007.

[12] W.M. Schniedewind, A. Burke and R. R. Cargill. "The Qumran Visualization Project". Fecha de consulta: 20 de junio de 2007. URLs: www.nelc. ucla.edu/qumran/ 